\title{
INVESTIGATION INTO STRUCTURAL FORMATION OF SOCIAL RELATIONS OF THE ELDERLY (CASE STUDY, GOLSAR VICINITY, RASHT, IRAN)
}

\author{
M. Djavad Saghafi ${ }^{1}$, S. Ahmadpour ${ }^{*}, 2$ \\ ${ }^{1}$ Professor of Architecture, Faculty of Architecture, Honar haye Ziba Campus, University of \\ Tehran, Iran \\ ${ }^{2}$ Master of Architecture, Faculty of Architecture, Farabi Campus, University of Tehran, Iran
}

Published online: 15 February 2017

\begin{abstract}
The present study aims to investigate the structural formation of the vicinity and promoting the social relations among the elderly residing there. In the present study the factors affecting the establishment of social relations among those over 60, using the questionnaire handed out, interviews and field observations, each of which was studied separately. The sample size was determined with accuracy of about 99 and error of one percent. Simple randomized sampling was employed, accessible to the elderly. The results obtained from questionnaires were analyzed using SPSS Vr 24; moreover, methodology and research Hypotheses were implemented through ANOVA table, Pearson Correlation and Regression. The validity of the research was therefore confirmed relying on Chronbach's alpha 0.87. This study also aims at identifying the factors affecting social relations, and interrelations thereof, as well as the extent of correlation of the defined indices (green space, variety of applicability, walk-ability). The results indicate that of all three indices, green space has the most contributing role in forming the social relationship among the elderly, whereas walk-ability marked the least.
\end{abstract}

Keywords: Social relation, Elderly, Green space, Walk-ability, Usage diversity, Golsar.

Author Correspondence, e-mail: sahar.ahmadpour69@gmail.com

doi: http://dx.doi.org/10.4314/jfas.v9i1s.718 


\section{1-INTRODUCTION}

Some have deemed agedness as the most prominent natural resource that is very often neglected. The changes sustained in the appearance of a person the roles they take up have made the society turn a gradual blind eye on their fundamental position in the society. As to the relative increase of the population of such people in many countries, it is projected that by the year 2020 there will have been up to one billion elderly; therefore, this has received huge attention of those in charge as well as planners.

The age 60-65 is referred to the incipient years of being called old, conforming to the retirement age. Otherwise put, the elderly are those having reached the age 60 or over [1]. Reportedly, as released by Iranian center of statistics in a survey conducted in 2006 the number of the elderly (over 60) was estimated to be 5.1 million, accounting for 7.3 percent of the population. If this trend continues, we will soon be facing a phenomenon called the population of the elderly [2].

Considering the prolonging life span of the elderly, it entails a comprehensive planning so as to control the life quality thereof. Such people, nowadays, are leading healthier lives than the generations before since the advent of technological advances has provided them with unfettered access to means; moreover, better education and more financial support has served a key role in this regard.

Delving the causes affecting the index of life expectancy and the quality of their life has assumed a highly significant position. Given the factors noted, the extent of social relations and interactions has been regarded as one of the most critical ones. In the present study, the endeavor is made to, through studying the target vicinity, identify and investigate the structural factors that affect the formation of social relations

\section{1-1- The relationship between life quality and social relations:}

In myriad studies implemented, the quality of life has been defined in different ways among which the following can be mentioned in six categories

A) Normal life: The power to fill the basic need of sustaining well-being and health as well as focusing on functional abilities

B) Social appeal: the power to make a socially useful life and playing an effective role in society as well as enjoying suitable occupation

C) Happiness: the interaction between excitement and depression, affected by internal and external factors for a short period of time 
D) Satisfaction with life: Positive attitude of person towards life quality, and personal capabilities, satisfaction with different aspects of life like love, marriage, friendships, jobs and so on

E) Attaining personal goals established in advance: the power to reach the goals, selfsatisfaction, self-aplomb, self-content in comparison with others, the narrowest gap possible between the reality and person's expectations

F) Inherent talents: the capabilities and physically and mentally potential and visible talents [3].

The social relations and interactions are an integral component for all age ranges, the effect of which especially among the elderly are effective in increasing the life quality of this generation. There is considerable evidence that shows that society's support as a whole plays a big part in health and well-being and consequently in the quality of life; social seclusion leads to maladies [4].

Drawing attention to social dimension of health and well-being has assumed a focal point. Cobb puts it as social that is named a cognition that leads a person to believing respect and the interest vented by others is a valuable element that goes to a network of mutual relations and commitments He emphasizes that increasing papers published in various journals about social support, the positive impacts of presence and reversely negatives of absence, are all indicative of the fact that social parameters have found an important position in the lives of the people [5].

\section{1-2-The main effect model:}

According to this model, the positive impacts of social support or lack of social seclusion results in increased life quality, and the relation between the quality of life and social support is linear [6].

Fleming and Baum, the two theoreticians of great fame, contend that those having social support will have an improved life quality and higher well-being [7]. People's excessive obsession with social networks such as networks connecting friends, families and cementing neighbor-to-neighbor bonds lay the grounds for people to have more support, and thus a healthy life [8]. According to the studies adapted from this model, those in supportive networks are less prone to depression, and have more mental well-being than those who are not in networks as such [9]. 


\section{1-3- The studies conducted to improve the social relations in the vicinity:}

A variety of experts in different field have tried to study different factors, in the vicinity, affecting social relations, thereby pronouncing different ideas. Differentiating public areas and urban areas, only those appropriate for social relations get higher priority therefore deemed as urban area. Public areas, having the potentials to be named, are at the very onset suitable for providing the citizens with the opportunity to establish and maintain interactions, though unsustainable and vulnerable. Following the phase where the social interactions are established through the social, economic, and cultural norms that give rise varied behavioral patterns pave the grounds for more coherent and sustainable social relations [10]. Occasional formal and informal meetings lay the foundations of developing friendships and routine relations. Meeting the needs of humans to friends and being in company of others necessitates a structural framework; in this regard public urban areas have the highest capacity. Relaxing ambience, privacy and control of the means serve a pivotal role in meeting the needs of humans to rest and relaxation [11].

Design of the neighborhood and the district, known as environmental design, plays a significant role in persuade/dissuade the neighbors to have interaction with each other. This matter has been surveyed by experts in different fields for instance; public health [12], [13], [14], city planning [15], [16], sociology [17], psychology [18], and architecture [19]. A better understanding of this role can provide appropriate condition to improve the socialization.

\section{1-4- Physical potential influence in shaping social relations:}

\section{1-4-1- Green space:}

Local gardens are the places of getting familiar with each other, engaging in groups and different social strata [20]. Appropriate green places in quarters as the center place can provide a position to create a positive and informal social interaction [21]. Park is a place to pause and manifestation of residences social character, as an arena for presenting people and a local node. The atmosphere of local parks is an arena for human life among buildings, daily activities, walking, short stays, and simple community relations [22].

Plant existence, tree and nature elements in public places encourage individuals to be present there. There is a direct correlation between using public places and the time of their presence with the number of trees and their position styles. The presence of trees multiplies the use of public places; subsequently, this circumstance brings about maximizing social solidarity in such region by enhancing the use of public places and presence of people [23]. 


\section{1-4-2- Walkability:}

Design indexes of vicinity environment and area associate with the ability to walk around them, the number of the sidewalks and their quality. This capability will attract residences to spend a portion of their time to walking around their environment and their neighborhood [24], [25]. As a result, the possibility of having random and daily relations with neighbors will increase and close relationship will form [24].

The correlation between the habit of walking, physical environment and social relationships among 609 individuals of Atlanta habitants in Georgia was assessed in a survey carried out in 2010. The results achieved from investigating confirmed the hypothesis of relation between the tendencies to social relationships and pleased walking in neighborhood surroundings [14].

\section{2- METHOD:}

\section{2-1- Physical and structural factors examined in this research:}

Observations and studies, two branches of green spaces and walking have been opted as a confirmed item and impressive in creating social relationships. Regarding to surveys, the existing of meaningful relation between lifestyle and daily habits in forming and reinforcing of third index of social relationships has been considered as usage diversity which refers to service and trading users in living area.

Impact indexes in promoting social interactions questioned are as following:

A) Existence green and open space in the regions such as parks, gardens, etc. (green space)

B) The ability of walking in area (walkability)

C) Usage diversity through the area (usage diversity)

According to identified findings of previous studies and the author opinion, these three factors were edited and considered through questionnaires in 18 questions.

\section{2-2- Case study of Golsar region in Rasht city (Iran):}

The area called Golsar today, is located in a triangular-shape region with approximately 608 hectares in north-west of Rasht. Zarjoob river forms the west edge of this triangular and Shahid Ansari Blv which is placed along the Rasht-Anzali road, forms the east edge of that. At the moment, Golsar region has the population of about 33000 people. This quarter is reputed as a part of regular and designed place of Rasht. 3 parks in distinct sectors of this region have been built that during the day many people including senile spend their time there. Around of this region, it is seen diversity users such as residential, trading (super market, bakery, barber shop, restaurant, etc.) and office. This diversity of places resole much 
of daily requires of habitants. Attention to manufacturing continuum sidewalks in more spots is an obvious feature of Golsar region. Based on observations, more residences, especially elders, walk in order to get to work or do their daily works.

\section{2-3-Research Methodology:}

In the present research, 120 questionnaires randomly distributed between elderly residents of Golsar region of Rasht. 18 questions of the questionnaire were codified in the form of Likert rating with five degree (very good to very poor) by interviewing of architecture and psychology professors. To prepare questionnaire, initially, the target table of content was prepared and research questions derived based on the table and 1 to 5 score has assigned in order to representing the responses in quantities. In the current study, analysis has been done by using the SPSS24 software. According to the inherent of research questions and investigation of social relationships, the Regression Model was used to evaluate the correlation between dependent and independent variables. Furthermore, in order to analyze the data, the ANOVA test, Pearson correlation test, average statics test and standard deviation were used. The reliability factor of present study is 99 percent, in the other words; one percent error is anticipated in the results.

The Cronbach's alpha of the questionnaire that initially distributed between 30 people, which has over 60 years old in the Golsar region is equal to 0.87 , which demonstrates the stability (reliability) of the questionnaire (Table1).

Table 1. Reliability of the questionnaire

\begin{tabular}{|c|c|c|}
\hline Cronbach's Alpha & $\begin{array}{c}\text { Cronbach's Alpha Based on } \\
\text { Standardized Items }\end{array}$ & number \\
\hline 0.87 & 0.87 & 18 \\
\hline
\end{tabular}

Kaiser-Meyer-Olkin (KMO), test of sampling adequacy, was used to investigate the suitability of the selected sample size. Moreover Bartlett's Test of Sphericity was applied to determine the correlation between the test materials in the society is not zero. According to Table 2, in this study, KMO is equal to 0.616 (more than 2) which is a reasonable amount (Table2). 
Table2. KMO and Bartlett's Test for testing the selected sample size

\begin{tabular}{|c|c|c|}
\hline \multicolumn{2}{|c|}{ Kaiser-Meyer-Olkin Measure of Sampling adequacy } & 0.616 \\
\hline \multirow{3}{*}{$\begin{array}{c}\text { Bartlett's Test of } \\
\text { Sphericity }\end{array}$} & Approx. Chi-Square & 1509,445 \\
\cline { 2 - 3 } & df & 153 \\
\hline
\end{tabular}

Based on the summery model table (Table3), correlation coefficient is equal to 0.936, which indicates a strong correlation between variables. The adjusted $\mathrm{R}$ square is equivalent to 0.874 that shows independent variables (green space, walkability and usage diversity) are about 0.874 from the total variance of dependent variable (Quality of social relationships).

Table3. Summery model for correlation between variables

\begin{tabular}{|c|c|c|c|c|}
\hline Model & $\mathrm{R}$ & $\mathrm{R}$ Square & Adjusted R Square & Std. Error of the Estimate \\
\hline 1 & 0.936 & 0.877 & 0.874 & 0.20618 \\
\hline
\end{tabular}

The ANOVA table shows the significance of entire model. The zero significance level (lower than 0.05 ) is indicate that independent variables (green space, walkability and usage diversity) are completely represent dependent variable (Quality of social relationships) (Table4).

Table 4. ANOVA test in order to show the significance of entire model

\begin{tabular}{|c|c|c|c|c|c|c|}
\hline \multicolumn{2}{|l|}{ Model } & Sum of Squares & df & Mean Square & F & Sig. \\
\hline 1 & Regression & 34.77 & 3 & 11.590 & 272.781 & 0.000 \\
\cline { 2 - 7 } & Residual & 4.886 & 115 & 0.42 & & \\
\cline { 2 - 7 } & Total & 39.656 & 118 & & & \\
\hline
\end{tabular}

According to the Pearson correlation table (Table5), high correlation rate is observed between the green space, walkability and usage diversity which maximum correlation rate is related to green space and its influence on the forming of social relationships. The significance level is expressed with $99 \%$ coefficient. (The zero assumption means no relation between variables and assumption 1 shows relations between variables, based on table, zero and one 
assumptions indicate rejection and confirmation, respectively). It should be noted that the significance of all variables are lower than 0.05 , which considered zero by the software automatically.

Table 5. Pearson correlation and significance of all variables

\begin{tabular}{|c|c|c|c|c|c|}
\hline Variable & & Green space & Walkability & $\begin{array}{c}\text { Usage } \\
\text { diversity }\end{array}$ & $\begin{array}{c}\text { Social } \\
\text { relation } \\
\text { quality }\end{array}$ \\
\hline & $\begin{array}{l}\text { Question } \\
\text { Number }\end{array}$ & 120 & 120 & 120 & 120 \\
\hline \multirow[t]{2}{*}{ Green space } & Pearson & 1 & 0.92 & 0.59 & 0.865 \\
\hline & Sig. & & 0 & 0 & 0 \\
\hline \multirow[t]{2}{*}{ Walkability } & Pearson & 0.92 & 1 & 0.59 & 0.778 \\
\hline & Sig. & 0 & & 0 & 0 \\
\hline \multirow{2}{*}{$\begin{array}{l}\text { Usage } \\
\text { diversity }\end{array}$} & Pearson & 0.59 & 0.59 & 1 & 0.798 \\
\hline & Sig. & 0 & 0 & & 0 \\
\hline \multirow{2}{*}{$\begin{array}{l}\text { Social } \\
\text { relation } \\
\text { quality }\end{array}$} & Pearson & 0.865 & 0.778 & 0.798 & 1 \\
\hline & Sig. & 0 & 0 & 0 & \\
\hline
\end{tabular}

\section{3- RESULTS AND DISCUSSION:}

The analytical model is illustrated the green space and their relatives factors with coefficient of correlation of 0.865 , possibility of walking around the neighborhood and its sub factors with correlation factor 0.778 , usage diversity and its sub factors with correlation factor 0.798 have influence on the improvement and forming of social relations of Golsar region (figure1). 


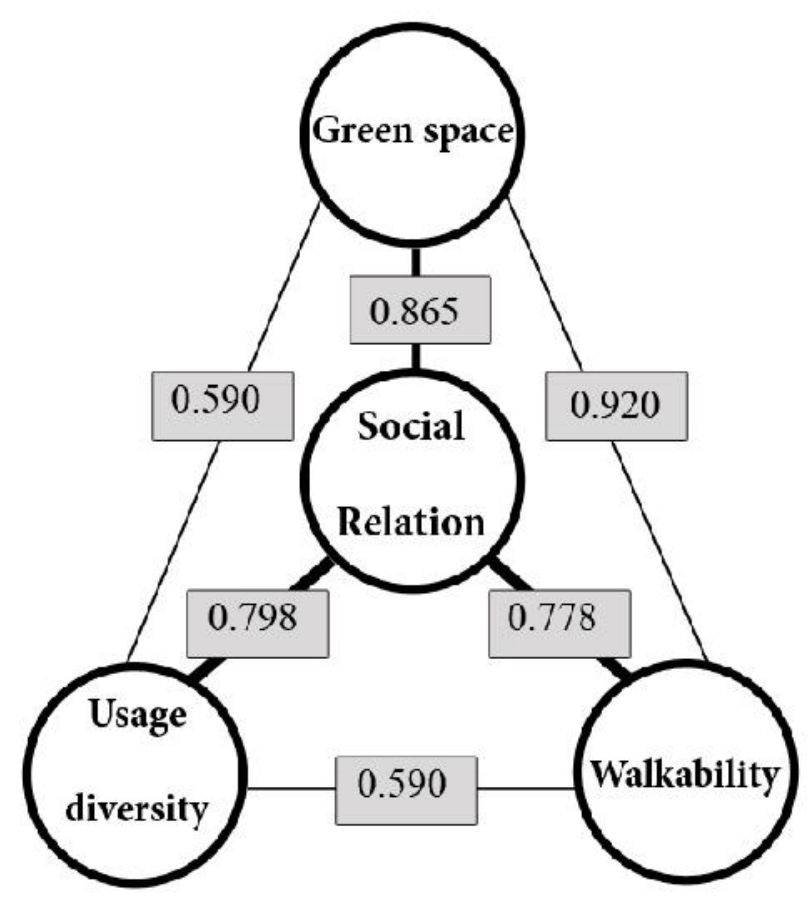

Fig.1. Analytical Model based on Pearson Correlation Table

According to the extracted analysis from field and survey studies achievements related to investigation of the impact rate of the quality of life of elders associated with three factors of green space, walkability and usage diversity practical is undeniable the existence of meaningful and impressive relation. Based on conducted analysis in research model, the questionnaire's parameters concerned to green space indicator have the most amount of effectiveness in forming social relationships as one of the quality life of index and also have the most impact of interact on two others indicators in walking and usage diversity. In this regard, the usage diversity index is located in second stage and eventually the possibility of walking.

\section{3-1- Analysis of parameters related to green space:}

Considering this point that all analyzed parameters in this chart has far more positive effect on promoting main index than meaningful level. In this graph, the impact of two parameters (diversity and density of vegetation) and (children's playground) accounted for the most correlation on direct effect of green space index in gaining social relationships (Figure2). This matter reflects a direct and reciprocal correlation of the quality, design and attracting green space. The possibility of engendering of communication between two generations from two 
distinct ages who have the ability to have relationship suggest an increasing of tendency of elders to use of parks and gardens inside of the area.

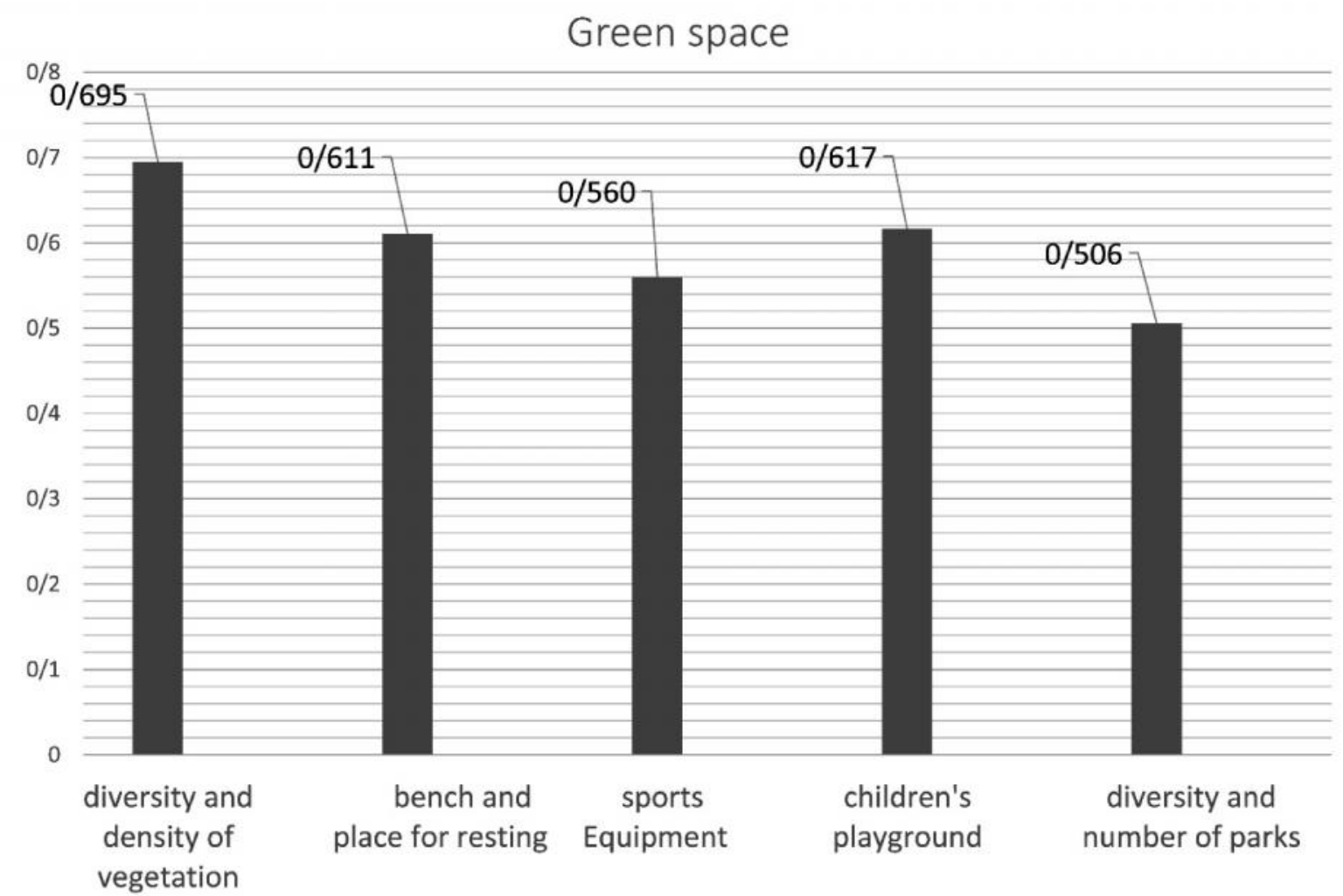

Fig.2. The correlation coefficient between parameters being questioned in the green space index

\section{3-2- Analysis of parameters related to usage diversity:}

The index related to existing diversity of users in habitats is highly depended on lifestyle and daily habits. According to statistical analysis, users like grocery store and supermarkets which are related to individuals daily needs directly, have the most impact on promoting of social relationships (Figure3). On the other hand, barbers and resorts such as café and restaurants have rarely any attraction for old people where can be defined and analyzed in contrast spot of young inclinations. 


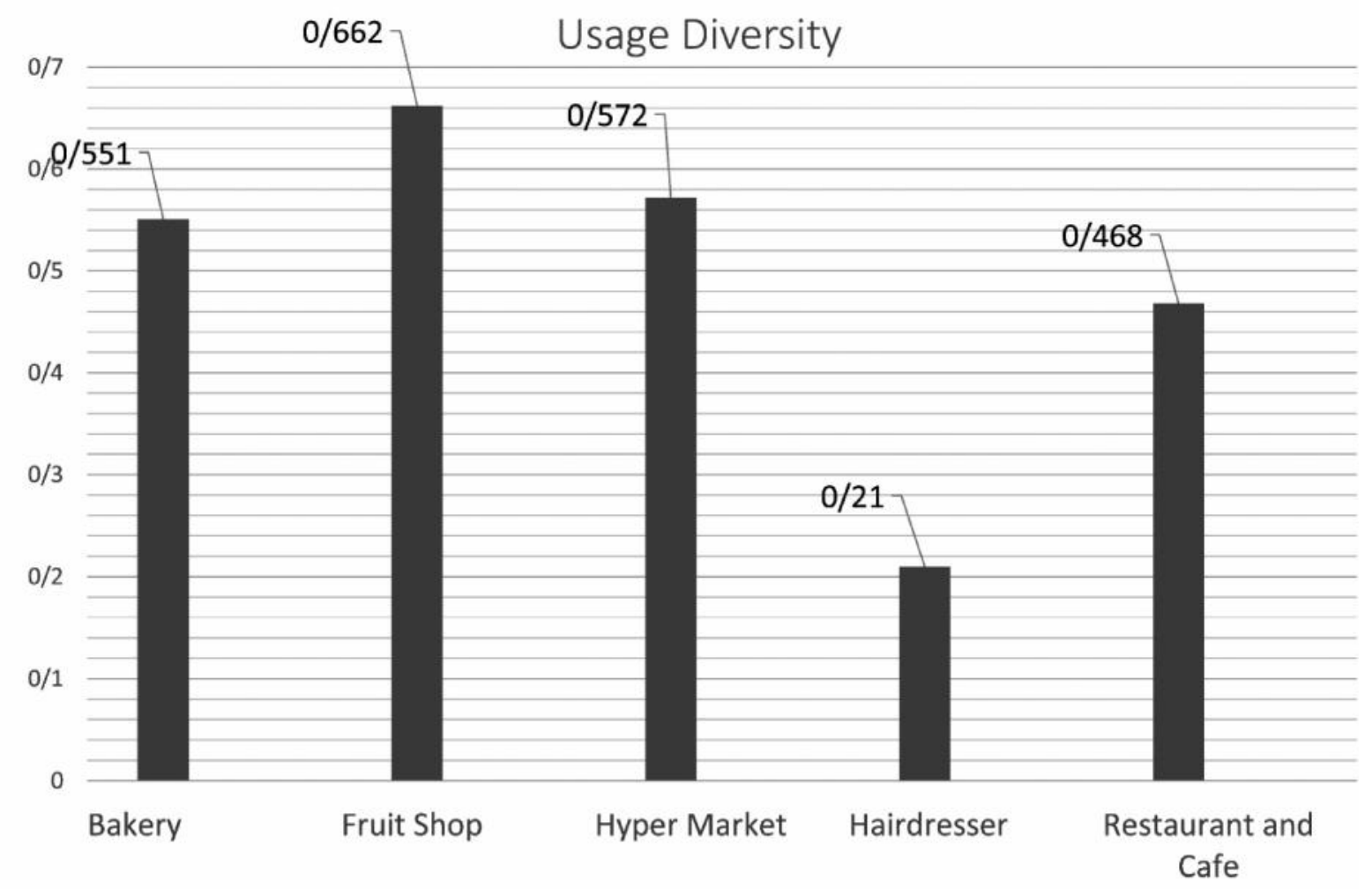

Fig.3. The correlation coefficient between parameters being questioned in the usage diversity index

\section{3-3- Analysis of parameters related to walkability:}

According to the extracted analysis from following graph, sidewalks was recognized as an effective factor in maximizing of social relationships in relating to doing walking as a daily and continuum activity (then having rest and refection on way) (Figure4). It is worth noting, according to the answers given to the question of walking with pets; this factor will have the least impact on intending of senile stratum to walk. Given risen from dominating cultural structure in society, this issue is justifiable. This matter is re-considerable for young generation, as well. 


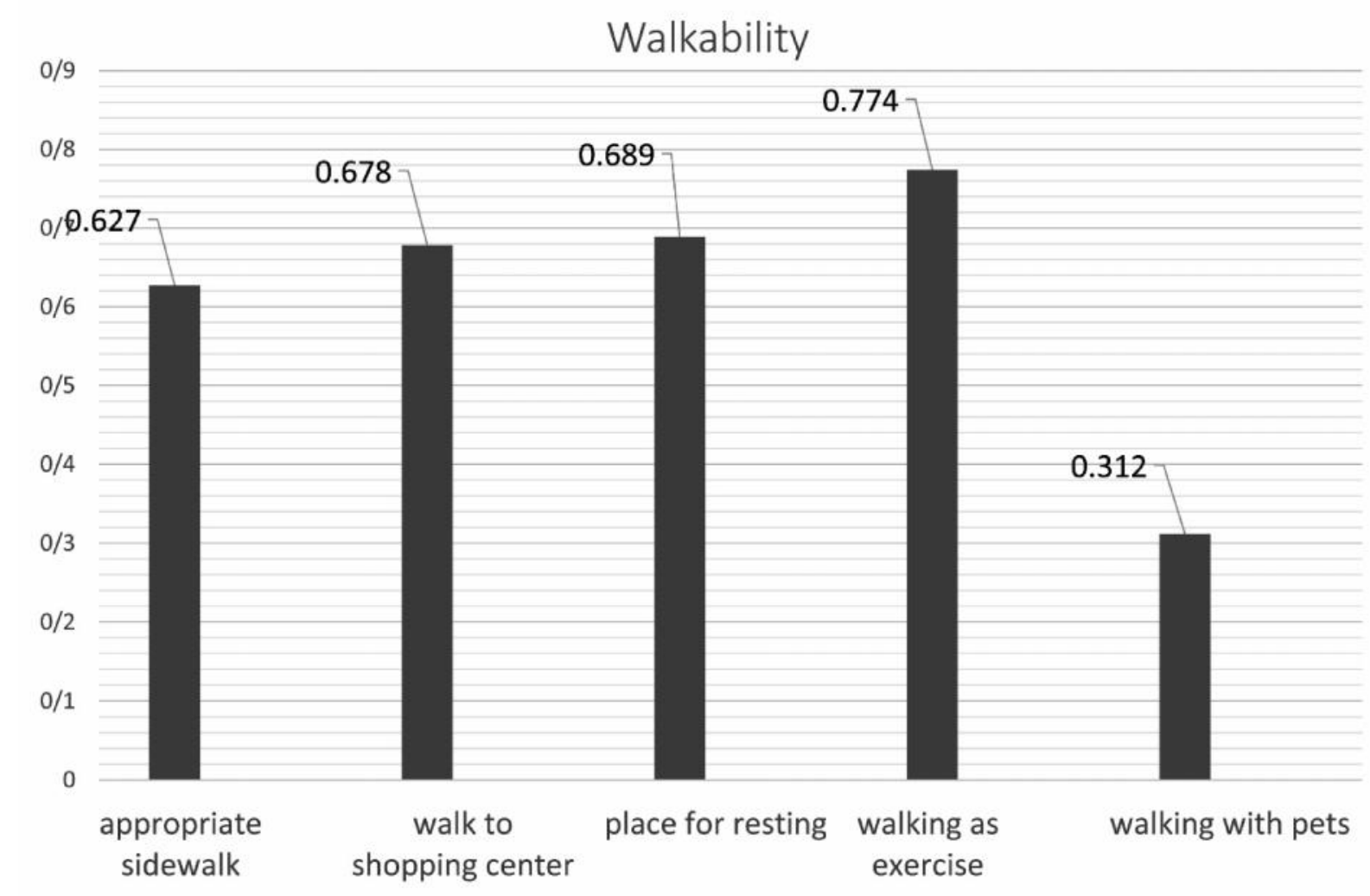

Fig.4. The correlation coefficient between parameters being questioned in the walkability index

According to the information mentioned above that the impact of each defined factor in correlation with questioned factors, it is possible to present consideration from designing suggestions in order to improve the structural of environment to develop social relationships. The results demonstrated the fact that a structural of environment has a straightforward effect on creating and extending social relationships. This effect will able to follow and impose through the architectural principle, observation and structural designing. The range of age is a determinative factor that sometimes seeks a different principle from other stratum of society. Meanwhile, there are the approaches of structural designing that can play a medium and moderation role in making welfare level for sections of society and a basis to producing effective social relationships to reach an active, unwearied and constituent society.

\section{REFERENCES:}

1) Shamloo,GH. (1985). what is aging? Why do we age? Tehran, Chehr. 130-145.

2- Jadidi A., Farahaninia M., Janmohammadi S.,Haghani H. (2012) The Relationship between Spiritual Well-Being and Quality of Life among Elderly People Residing in Kahrizak Senior House, Iran Journal of Nursing (IJN) Vol. 24, 48-56. 
3- Ferrans, C. E., 1996, Development of a conceptual model of Quality of life, Scholary inquiry of nursing Practice, Vol. 10, 243-304.

4-Avund, k. Damsgaard, M. T. \& Holstien.B.F. (1998). Social relation and mortality: An eleven year follow up study of 70 year old man and women in Denmark. Social science and Medicine. 47.635-643.

5- Cobb, S. (1976). Social Support as a moderator of life stress. Psychosomatic Medicine, 38, 300-314

6-Helgeson, V.S. (2003). Social support and quality of life, Quality of Life Research 12, 2531.

7- Fleming, R. \& Baum, Andrew. (1986). Social support and stress: The buffering effects of friendship. Friendship and social integration. New York: Springer verlag.

8- Montazeri, A (2009). "Social Determinants of Health", Tehran, Jahad Daneshgahi publicans, Vol 1, 189-212.

9-Thoits, P.A. (1982). Conceptual, methodological and theoretical problems in studying social support as a buffer against life stress. Journal of health and social behaviors. 23. 34-48

10- Ghanbaran AH (2004). Iranischer Basar im Wandel, Stuttgart.p.178 [Persian]

11- Whyte W (1980). Social Life of Small Urban Space, Conservation Foundation.

12- Corburn, J. (2004). Confronting the challenges in reconnecting urban planning and public health. American Journal of Public Health, 94, 541-546.

13-Dannenberg, A. L., Jackson, R. J., Frumkin, H., Schieber, R. A., Pratt, M., Kochtitzky, C., \& Tilson, H. (2003). The impact of community design and land-use choices on public health: A scientific research agenda. American Journal of Public Health, 93, 1500-1508.

14-Wood, L., Frank, L. D., \& Giles-Corti, B. (2010). Sense of community and its relationship with walking and neighborhood design. Social Science \& Medicine, 70, 1381-1390.

15-Appleyard, D., \& Lintell, M. (1972). Environmental quality of city streets: The residents' viewpoint. Journal of the American Institute of Planners, 38, 84-101.

16- Forrest, R., \& Kearns, A. (2001). Social cohesion, social capital and the neighbourhood. Urban Studies, 38, 2125-2143.

17-Sampson, R., \& Raudenbush, S. (1999). Systematic social observation of spaces: A new look at disorder in urban neighborhoods. American Journal of Sociology, 105, 603-651. 18-Fried, M. (2000). Continuities and discontinuities of place. Journal of Environmental Psychology, 20, 193-205. 
19-Evans, G. W., \& McCoy, J. M. (1998). When buildings don't work: The role of architecture in human health. Journal of Environmental Psychology, 18, 85-94.

20- Mahdavian, M (2012). Edited by: Keshavarz, L., Gardens as a social institution.

Educational and Research Conference Tehran landscapes.

21- Groenewegen, Peter, Agnes Even den Berg, Sjerp de Vries, and Robert Verhenji. (2006)

"Vitamin G: effects of green space on health, well-being, and social safety." BMC Public Health.

22- Suzanchi,K., Tariveh,S. (2012) Re-design of Neighborhood Parks with an Emphasis on Social Relationship Development in the Neighborhood Communities. Naghshe Jahan, Vol 1, 107-129.

23- Mass, Jolanda, Sonja M.E van Dillen, Robert Verhenji, and Peter Groenewegen. (2009) "Social contacts as a possible mechanism behind the relation between green space and health." Health \& Place 15.

24-Alfonzo, M. A. (2005). To walk or not to walk? The hierarchy of walking needs.

Environment and Behavior, 37, 808-836.

25-Saelens, B. E., Sallis, J. F., \& Frank, L. D. (2003). Environmental correlates of walking and cycling: Findings from the transportation, urban design, and planning literatures. Annals of Behavioral Medicine, 25, 80-91.

\section{How to cite this article:}

Djavad Saghafi M, Ahmadpour S. Investigation into structural formation of social relations of the elderly (case study, golsar vicinity, rasht, iran). J. Fundam. Appl. Sci., 2017, 9(1S), 662675. 